\title{
Geotecnologia aplicada à diagnose ambiental: Reserva Biológica de Pinheiro Grosso, Barbacena - MG
}

\author{
Geotechnology applied to environmental diagnosis: Biological Reserve of \\ Pinheiro Grosso, Barbacena - Minas Gerais - Brazil
}

\author{
Natália Oliveira Dias ${ }^{1}$ \\ Frederico Cássio Moreira Martins ${ }^{2}$ \\ Kelly de Oliveira Barros ${ }^{3}$
}

\author{
Palavras-chave \\ Área Protegida \\ Legislação Ambiental \\ Uso e ocupação do solo \\ Sistema de Informação Geográfica \\ Sensoriamento Remoto
}

\begin{abstract}
Resumo
As Unidades de Conservação são espaços territoriais que apresentam recursos naturais com características relevantes. Tais áreas são utilizadas como estratégia para a proteção da natureza. É neste contexto que o uso de geotecnologias, como os Sistemas de Informações Geográficas e o Sensoriamento Remoto, otimiza a diagnose e o monitoramento ambiental. O estudo analisou o uso e ocupação do solo assim como a fragilidade do cenário atual da Reserva Biológica (ReBio) de Pinheiro Grosso, localizada em Barbacena-MG. Atualmente, a ReBio apresenta $66,18 \%$ de sua área ocupada por Vegetação e $33,82 \%$ por Área antropizada. A Análise Multicritério revelou que $4,19 \%$ da ReBio estão fortemente sujeitos à antropização. Devido à grande pressão antrópica e conflitos socioambientais existentes, sua categoria de Proteção Integral não condiz com a sua atual situação. Sugere-se a delimitação da Zona de Amortecimento da unidade, a implantação emergencial de programas de educação ambiental para a comunidade local, assim como uma maior fiscalização e monitoramento da área, além de sua recategorização como unidade de Uso Sustentável.
\end{abstract}

\footnotetext{
${ }^{1}$ Instituto Federal de Educação, Ciência e Tecnologia do Sudeste de Minas Gerais, Brasil - Campus Barbacena. nataliaod@yahoo.com.br

2 Instituto Federal de Educação, Ciência e Tecnologia do Sudeste de Minas Gerais, Brasil - Campus Barbacena. frederico.martins@ifsudestemg.edu.br

${ }^{3}$ Instituto Federal de Educação, Ciência e Tecnologia de Mato Grosso, Brasil - Campus Campo Novo do Parecis. kelly.barros@cnp.ifmt.edu.br
} 


\section{Palavras-chave}

Protected Area

Environmental Legislation

Land Use

Geographic Information System

Remote Sensing

\begin{abstract}
The Protected Areas (PAs) are territorial spaces that present natural resources with relevant characteristics. Such areas are used as strategy for the environment protection. The use of geotechnologies, such as Geographic Information System and Remote Sensing, optimizes diagnosis and environmental monitoring. The study aimned to analyzed the use and soil occupation as well as the fragility of the current scenario of the Pinheiro Grosso Biological Reserve (ReBio - ReBio, in Portuguese), located in Barbacena - Minas Gerais state - Brazil. Currently, ReBio (ReBio, in Portuguese) areas presents $66.18 \%$ occupied by Vegetation and $33.82 \%$ by Anthropized area. Multicriteria Analysis revealed that $4.19 \%$ of the ReBio (ReBio, in Portuguese) are strongly subject to anthropization. Due to the great anthropic pressure and existing socio-environmental conflicts, its category of Integral Protection does not match its current situation. So, it is suggested the delimitation of unit Damping Zone, the emergency implementation of environmental education programs for the local community, as well as greater supervision and monitoring of the area, as well as its recategorization as a Sustainable Use unit.
\end{abstract}

\section{INTRODUÇÃO}

No Brasil, em 18 de julho de 2000, a Lei Federal $\mathrm{n}^{\circ} 9.985$ instituiu o Sistema Nacional de Unidades de Conservação da Natureza (SNUC), que estabelece critérios e normas para a criação, implantação e gestão das Unidades de Conservação (UC). As UC são espaços do território brasileiro em que seus recursos naturais possuem características relevantes, legalmente delimitadas pelo poder público. $\mathrm{O}$ objetivo destas áreas é a conservação, sob regime especial de administração, ao qual se aplicam garantias adequadas de proteção (BRASIL, 2000).

O SNUC, quando executado efetivamente, contribui para a proteção da natureza e para a conservação da biodiversidade no território nacional (RIBEIRO et al., 2010). No entanto, existe no Brasil uma grande dificuldade em gerir questões ambientais. A tentativa de atualização do
Código Florestal, a indevida exploração de recursos naturais no território, principalmente na Amazônia, e a ineficiência governamental no cumprimento da lei, são exemplos que ilustram este cenário. A revogação do antigo Código Florestal (Lei Federal $\mathrm{n}^{\circ}$ 4.771/1965) e a aprovação da Lei Federal n 12.651/2012 evidenciou significativo retrocesso ambiental e uma conjuntura de insegurança jurídica no país (BARROS, 2016; BRASIL, 1965; 2012; GOMES; MARTINELLI, 2012). Esta flexibilização da proteção de áreas de vegetação nativa reforça o viés político-econômico existente em detrimento à manutenção da integridade ambiental (SANTOS, 2012).

Apesar da criação do SNUC ser considerado um progresso na legislação ambiental brasileira, é possível observar pelos trabalhos de Bellinassi et al. (2011), Gonçalves et al. (2011), Silva et al. (2006), Simon (2001), Terra e Rozely (2011) que apenas a criação sucessiva de UC não garante o cumprimento 
das metas e dos planos estipulados em lei e que, na maioria dos casos, tais unidades acabam sendo precariamente geridas (DOUROJEANNI; PÁDUA, 2001). Sendo assim, apenas a criação das UC não é suficiente para proteger o patrimônio natural e cultural de uma nação (DEBETIR, 2006), sendo necessários sua efetiva sua implementação e fiscalização (FARIA, 1997).

No município de Barbacena, localizado em Minas Gerais, a Lei Municipal n ${ }^{\circ} 2.250$ de 30 de novembro de 1987 criou a Reserva Biológica (ReBio) de Pinheiro Grosso, pertencente ao grupo de Proteção Integral das UC (BARBACENA, 1987). Esta ReBio tem demandado imprescindível atenção no que se refere o seu controle. Sua localização é estratégica quanto à proteção da fauna e da flora, já que está inserida no devastado bioma Mata Atlântica, além de localizada em uma das cabeceiras do Rio das Mortes, pertencente à bacia hidrográfica do Rio Grande. Apesar de sua relevância do ponto de vista ecológico, esta UC está sob significativa pressão antrópica e apresenta problemas elementares na sua gestão.

O Sistema de Informação Geográfica SIG, a Cartografia Digital, o Sensoriamento Remoto e o Sistema de Posicionamento Global -
GPS são amplamente utilizados em estudos ambientais. Diversos autores, inclusive no âmbito das UC, têm empregado essas geotecnologias por auxiliarem na gestão, na implementação, na delimitação, no zoneamento, no manejo, no planejamento e na fiscalização, otimizando o diagnóstico e monitoramento dessas áreas (ARAGÃO; DUARTE, 2016; BALDWIN et al., 2014; KHANDAY; JAVED, 2016; REIS; COSTA, 2017; VENTICINQUE et al., 2016).

Nesse sentido, este estudo objetiva, por meio de geotecnologias, caracterizar os atuais usos da ReBio de Pinheiro Grosso e apresentar sua vulnerabilidade à antropização, gerando informações para auxiliar em futuras tomadas de decisão.

\section{MATERIAL E MÉTODOS}

A ReBio de Pinheiro Grosso localiza-se na cidade de Barbacena - MG, no Distrito de Pinheiro Grosso (Mapa 1), compreendida entre a latitude $21^{\circ} 15^{\prime} \mathrm{Sul}$ e longitude $43^{\circ} 45^{\prime}$ Oeste, esta ReBio perfaz uma área de 479 hectares (ha), com altitude média de $1.126 \mathrm{~m}$. 
Mapa 1 - Localização da Reserva Biológica de Pinheiro Grosso, Barbacena-Minas Gerais.

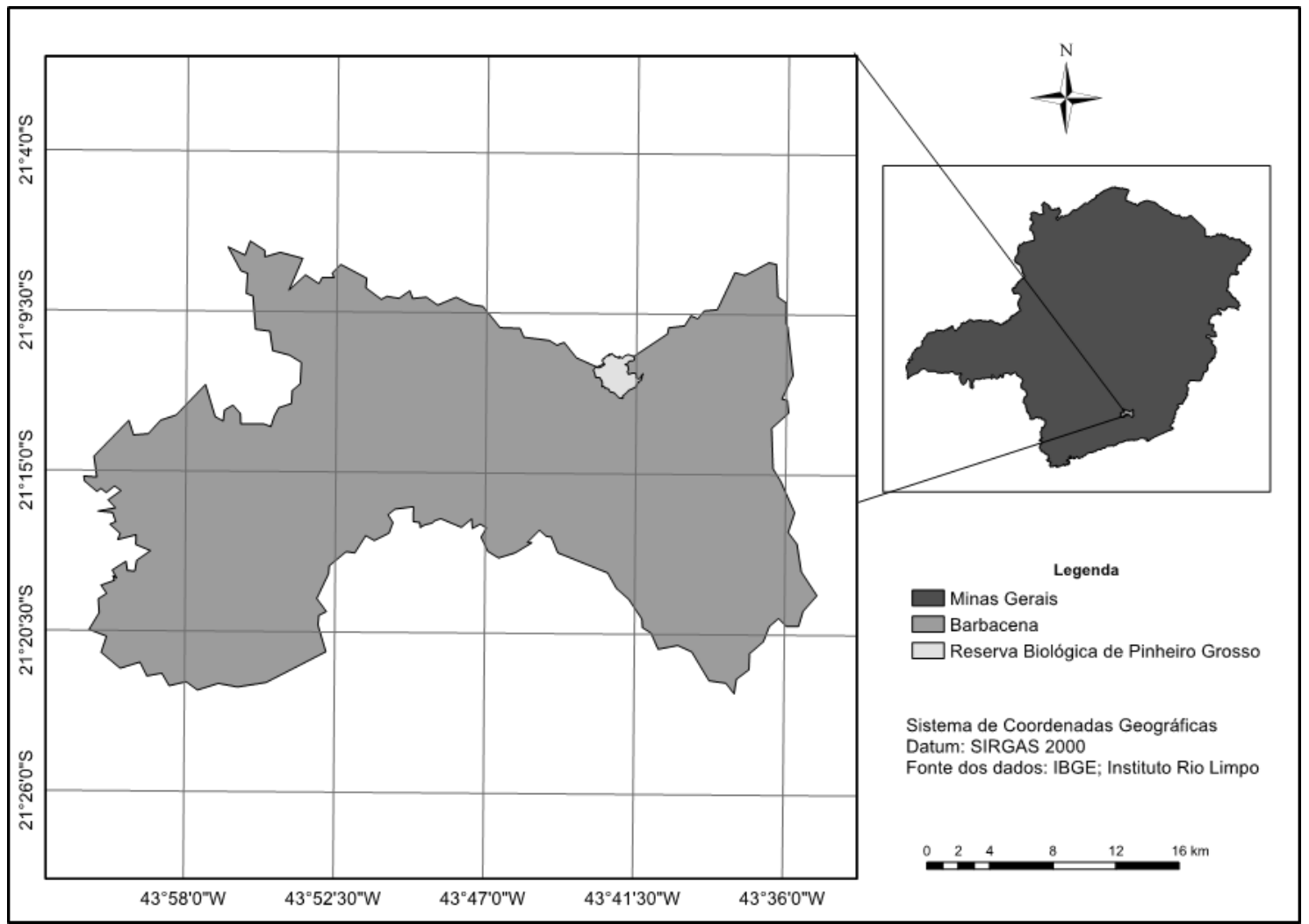

Org.: do Autor, 2019.

\section{Delimitação da área de estudo}

A delimitação da área de estudo foi feita a partir das informações do Plano de Manejo e documentos referentes à UC, consultas à órgãos municipais e visitas in loco. Foi utilizado o aparelho de navegação, receptor do sinal GPS, marca Garmin ${ }^{\circledR}$, modelo eTrex 30 nas visitas in loco. O processamento das coordenadas referentes ao limite da área de estudo foi inicialmente realizado em planilha eletrônica e, posteriormente, no software ArcGIS, versão 10.5.1. O sistema de coordenadas e de referência adotados foram, respectivamente, o Sistema de Coordenadas Geográficas e o Sistema de Referência Geocêntrico para as Américas, Datum - SIRGAS 2000. As coordenadas foram processadas no componente
ArcMap do ArcGIS, por meio da ferramenta Projections and Transformations - Define Projection, contida no módulo Data Management Tools.

\section{Obtenção e Classificação de Imagens Digitais}

A caracterização da área de estudo foi realizada por meio da classificação de imagens digitais de alta resolução, sendo estas de resolução espacial no modo multiespectral (Azul, Verde, Vermelho e Infravermelho próximo) de 2,0 m a nadir, disponibilizadas pelo software ArcGIS, no acervo - DigitalGlobe/Esri, oriundas do satélite: GeoEye/sensor Multiespectral.

A imagem foi processada e a área de interesse extraída, utilizando como referência 
as coordenadas relativas à poligonal da ReBio. Neste processo, utilizou-se o componente ArcMap, por meio da ferramenta Extraction Extract by Mask, contida no módulo Spatial Analyst Tools.

Para determinação das classes, foi adotado o Método de Classificação Supervisionada. O classificador utilizado foi a Máxima Verossimilhança. Foram determinadas duas classes: 1) Área antropizada, correspondente à ocupação humana, como casas, ruas, solo exposto, plantios agrícolas ou pastagem; e 2) Vegetação, referindo-se àquelas áreas formadas por vegetação nativa ou plantada, já que o classificador não foi capaz de diferenciá-las. A partir de amostras de treinamento, o processo foi realizado por meio da ferramenta Image Classification, encontrada na Toolbars, do módulo Spatial Analyst.

\section{Geração de mapas temáticos e Análise Multicritério}

A Análise Multicritério (AM) foi orientada pela Análise Hierárquica de Pesos (AHP), método este desenvolvido por Thomas Saaty (1978). Esta metodologia auxilia na atribuição dos pesos dos planos de informação para determinar a sua influência em cada um dos critérios estabelecidos (MOURA, 2007).

Para tanto, inicialmente os dados foram organizados e processados, em ambiente SIG, por meio do estabelecimento de critérios. Os pesos associados aos critérios foram atribuídos com base em seu nível de influência na fragilização do ambiente (Tabela 1).
Tabela 1 - Pesos atribuídos aos níveis de influência para Análise Multicritério.

\begin{tabular}{cc}
\hline Pesos & $\begin{array}{c}\text { Nível de influência na fragilização } \\
\text { do ambiente }\end{array}$ \\
\hline 1 & Pouca \\
2 & Baixa \\
3 & Média \\
4 & Forte \\
5 & Muito Forte \\
\hline
\end{tabular}

Fonte: Adaptado de MOURA, 2007.

Geraram-se buffers para as zonas de servidão contidas dentro da UC, normatizadas por cada empresa, sendo: $60 \mathrm{~m}$ da faixa de limpeza da Companhia Energética de Minas Gerais (CEMIG), para tensões acima de $345 \mathrm{Kv}$; $20 \mathrm{~m}$ para o Gasoduto da Petróleo Brasileiro S.A. (PETROBRAS) e $15 \mathrm{~m}$ para a rodovia MG 132. Tais áreas, assim como a área ocupada pela comunidade dentro da ReBio, receberam na AM o maior peso, Peso 5. Tal atribuição justificou-se pelo fato destas áreas já terem a ocupação antrópica consolidada e, consequentemente, apresentarem, nas áreas circunvizinhas, uma maior vulnerabilidade a alterações ambientais (Tabela 2).

Tabela 2 - Pesos de acordo com a influência segundo a análise dos níveis de influência.

\begin{tabular}{cc}
\hline Critério & Peso \\
\hline Área Antropizada & 5 \\
CEMIG & 5 \\
Declividade & 4 \\
Gasoduto & 5 \\
Hidrografia & 5 \\
Rodovia & 5 \\
Vegetação & 1 \\
\hline
\end{tabular}

Org.: do Autor, 2019.

Para extrair a declividade foi gerado um Modelo Digital de Elevação (MDE) a partir de 
dados da Shuttle Radar Topography Mission (SRTM). O interpolador utilizado foi o Topo to Raster, localizado no módulo Spatial Analyst Tools - Interpolation. Posteriormente, por meio da ferramenta Reclassify, a declividade foi extraída do MDE. As áreas que apresentaram inclinação abaixo de $20^{\circ}$ foram selecionadas e, na AM, atribuída a elas Peso 4, em razão de serem áreas de ocupação preferencial tanto da população para moradia quanto da atividade agrícola. Por meio desta mesma justificativa, foi atribuído o Peso 5 ao critério Hidrografia. Este critério adotou um buffer de $30 \mathrm{~m}$ a partir dos cursos d'água existentes (Tabela 2).

No que se refere à vegetação, esta recebeu Peso 1, com nível de influência caracterizado em "Pouca", tendo em vista tanto a Lei da Mata Atlântica (Lei Federal no 11.428, de 22 de dezembro de 2006) que protege os remanescentes deste bioma quanto o próprio propósito de uma ReBio. Assim, entende-se que, entre todas as classes, a Vegetação é aquela de menor vulnerabilidade à alteração ambiental (Tabela 2). Vale observar que todos estes pesos foram atribuídos utilizando a ferramenta Reclassify.

Em seguida, por meio da ferramenta Weighted Overlay, do módulo Spatial Analyst, foi realizada a sobreposição ponderada dos critérios de acordo com os pesos pré-definidos. Assim, um mapa com as classes: Alto risco de antropização, Baixo risco de antropização e Área antropizada foi gerado. Ressalta-se que, nesta etapa, todas as infraestruturas e a área ocupada pela comunidade foram identificadas por meio da fotointerpretação.

\section{RESULTADOS E DISCUSSÕES}

A partir da delimitação realizada, a ReBio de Pinheiro Grosso possui 479 ha. Destaca-se a inexistência de qualquer documento oficial formalizando os limites desta ReBio. Tal fato mostra a precariedade de informações sobre a unidade, já que a delimitação de uma UC é algo elementar para qualquer ação a ser tomada, inclusive a sua própria criação.

Dos 479 ha da ReBio de Pinheiro Grosso, $66,17 \% \quad(317$ ha $)$ correspondem à classe Vegetação e, 33,82\% (162 ha), à classe Área antropizada (Mapa 2). Diante destes valores é possível presumir a grande pressão antrópica e os inúmeros conflitos socioambientais que existem na ReBio. As Reservas Biológicas, por pertencerem à categoria mais restritiva do SNUC, não admitem a exploração dos seus recursos naturais ou mesmo a moradia dentro de seus limites.

A maior parte da população do distrito se concentra dentro da unidade, ocupando uma área de 41,55 ha, o que representa $8,67 \%$ da área total (Mapa 3). Embora a Zona de Amortecimento (ZA), corresponda a uma área que tem como objetivo minimizar os impactos negativos sobre a unidade, tal área ainda não foi estabelecida para a ReBio de Pinheiro Grosso. Ressalta-se que, da mesma forma que o interior de uma UC, a ZA também possui normas e restrições específicas quanto ao desenvolvimento de atividades humanas. Como pode ser observado no Mapa 3, seja em seu interior ou em uma faixa limítrofe à ReBio que corresponde a um potencial ZA da unidade, existem várias propriedades privadas, com o 
predomínio de pastagens, o que também implicaria em conflitos quando da definição da ZA. Dentro deste contexto, vale mencionar que, apesar do Plano de Manejo da ReBio de Pinheiro Grosso ter sido criado apenas em 2006 e ainda não estar implantando, o SNUC determina que a ZA pode ser definida na criação da unidade ou posteriormente (art. 23,
$\S 2^{\circ}$ ) (BRASIL, 2000).

Em outra perspectiva é possível analisar a fragmentação da vegetação nativa nas proximidades da ReBio de Pinheiro Grosso (Mapa 3). Porém, é perceptíveis grandes fragmentos de mata inclusive já conectados à unidade, assim como outros fragmentos bem próximos com grande potencial de conexão.

Mapa 2 - Uso e ocupação do solo na Reserva Biológica de Pinheiro Grosso, Barbacena - MG.

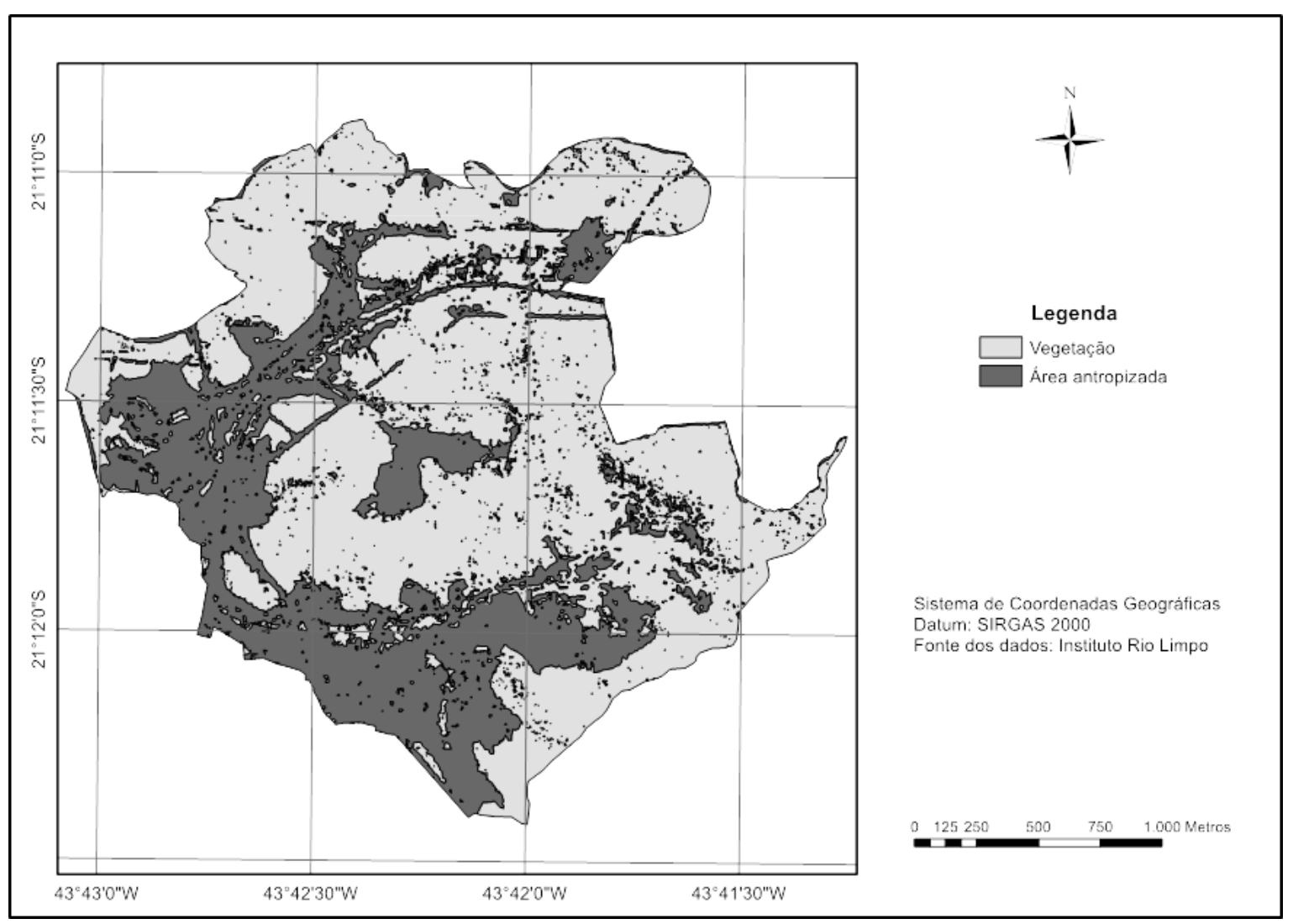

Org.: do Autor, 2019. 
Mapa 3 - Imagem de satélite da Reserva Biológica de Pinheiro Grosso, Barbacena - MG, e a área de entorno.

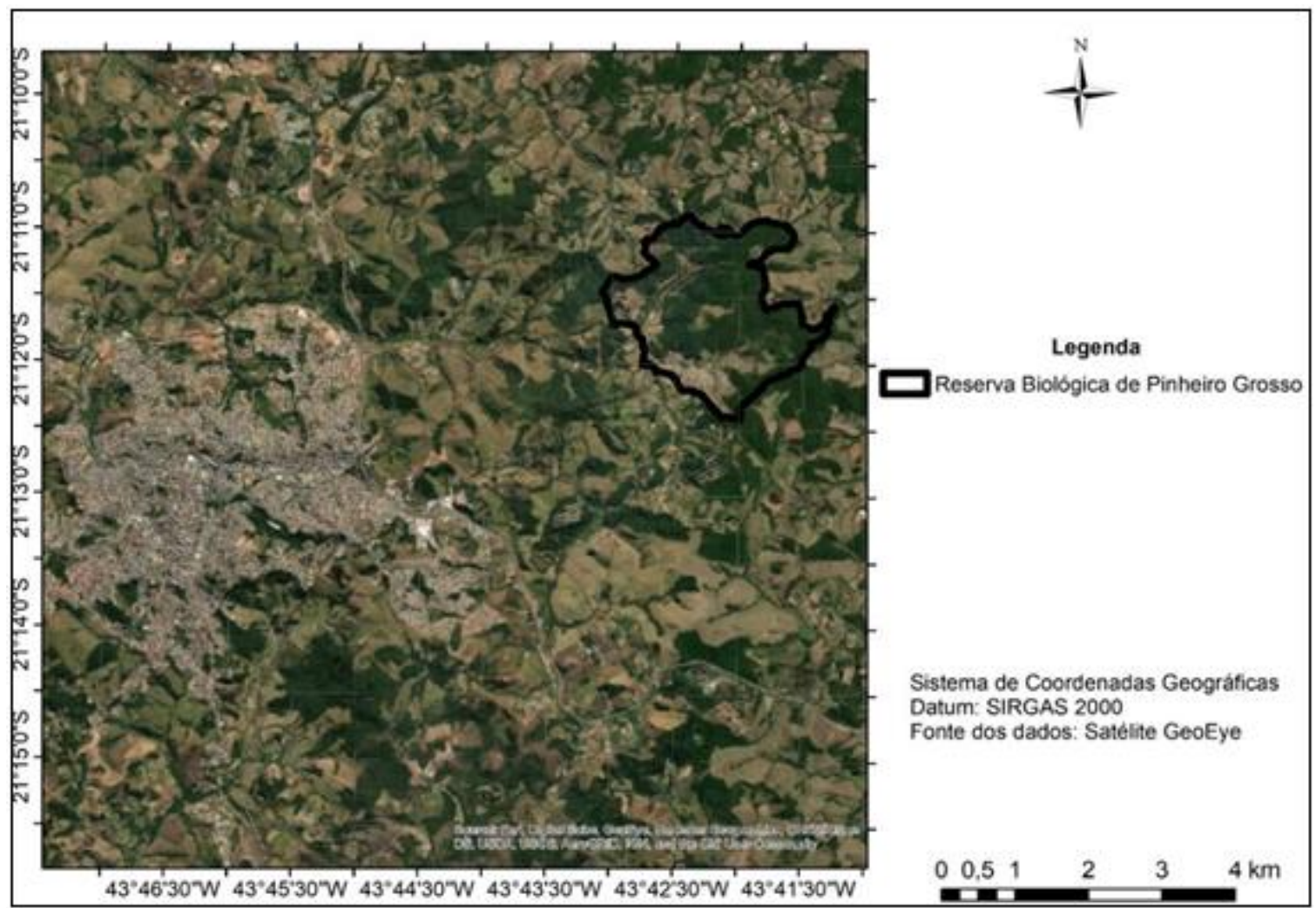

Org.: do Autor, 2019.

Outras UC também demostraram casos de conflitos de uso e ocupação do solo, tais como os encontrados na ReBio Pinheiro Grosso. Um exemplo pode ser demonstrado pelo trabalho de Santiago et al. (2007) em um estudo realizado na ReBio Mata do Poço D'anta, localizada em Juiz de Fora (MG), onde foi apontado a existência de conflitos no interior da unidade, sendo constatado vias pavimentadas, campo de futebol, fábrica de concreto da Prefeitura Municipal e um horto com produção de mudas, dificultando a gestão da mesma. Barros e Barbosa (2015) relataram a situação da ReBio do Gurupi (MA) que, além de sofrer com o baixo volume de estudos e informações disponíveis, tal como a UC estudada neste trabalho, esta apresenta um elevado índice de desmatamento, como indicou o relatório sobre Desmatamento e Mudanças Climáticas, entre os anos de 2000 e 2004. Iwama et al. (2014), em estudo realizado no Parque Estadual da Pedra Branca (RJ), identificaram o aumento das moradias e de pessoas ao longo dos anos, com moradores das classes alta à baixa e o desenvolvimento de agricultura dentro dos limites do parque. No Rio Grande do Sul, Flores et al. (2009) apresentaram, entre outros aspectos, a questão dos conflitos de uso do solo no Parque Nacional da Lagoa do Peixe e Parque Natural Municipal Tupancy. Atividades como a agricultura, a pecuária extensiva, a pesca, o florestamento com vegetação exótica (Pinus), o turismo sem 
qualquer controle e a própria urbanização associada com a pressão imobiliária foram apontadas pelos autores como responsáveis por gerar conflitos nestas unidades que também são de Proteção Integral.

No caso da ReBio de Pinheiro Grosso, embora mais de $60 \%$ da unidade corresponda à Vegetação, toda esta classe não equivale à vegetação nativa, tendo em vista a existência de florestas plantadas dentro dos seus limites (Tabela 3; Mapa 4).
Tabela 3 - Infraestruturas no interior da ReBio e suas respectivas áreas.

\begin{tabular}{ccc}
\hline Infraestruturas & $\begin{array}{c}\text { Área } \\
\text { (ha) }\end{array}$ & $\begin{array}{c}\text { Área } \\
\text { total (\%) }\end{array}$ \\
\hline Fazenda da PMB & 33,14 & 6,91 \\
CEMIG & 20,44 & 4,26 \\
Fundação João XXIII & 11,85 & 2,47 \\
Antiga Estação de & 11,52 & 2,34 \\
Fruticultura da UFV & 4,68 & 0,97 \\
Gasoduto & 4,15 & 0,86 \\
Viveiro PMB & 3,35 & 0,69 \\
CRESCEP & 3,22 & 0,67 \\
Rodovia MG 132 & 3,07 & 0,64 \\
Viveiro Florestal IEF & 3,00 & 0,62 \\
Sindicato dos Trabalhadores & 1,21 & 0,25 \\
Lixão desativado & $\mathbf{9 9 , 6 3}$ & $\mathbf{1 0 0}$ \\
TOTAL & &
\end{tabular}

Org.: do Autor, 2019.

Mapa 4 - Infraestruturas na Reserva Biológica de Pinheiro Grosso, Barbacena-MG.

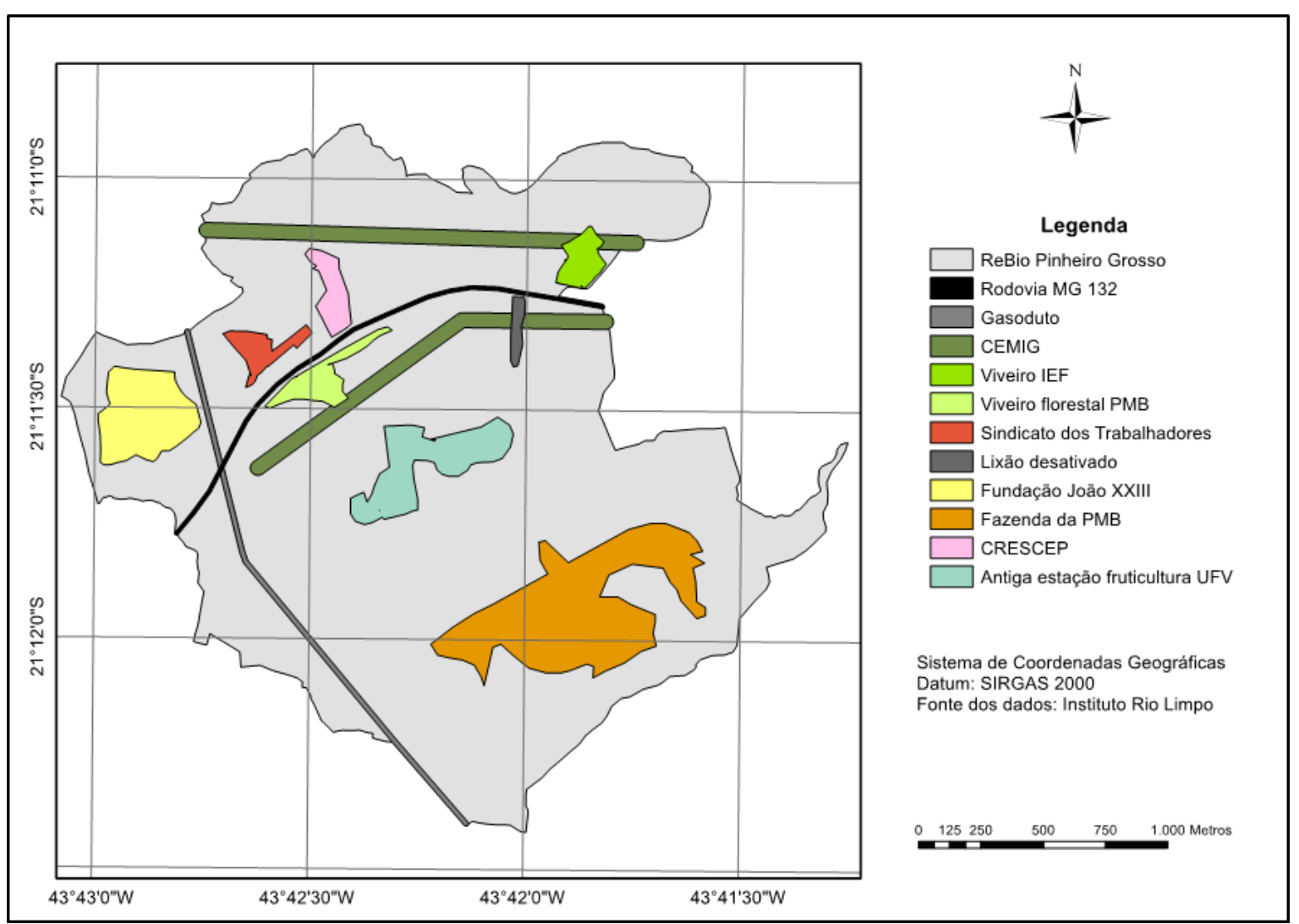

Org.: do Autor, 2019.

Em relato do Diretor da Secretaria de Meio Ambiente de Barbacena, apresentado no trabalho realizado por Silva e Silva (2014) sobre a ReBio de Pinheiro Grosso, foi explicitada a origem de várias destas infraestruturas que ainda hoje se encontram dentro dos limites da unidade. Como a área inicialmente pertencia à Prefeitura, várias doações foram feitas antes da 
criação da UC. O Diretor ainda destacou que a ReBio de Pinheiro Grosso foi criada para proteger nascentes do impacto da expansão da comunidade local. De acordo com Silva e Silva (2014), em Barbacena, os interesses políticos assim como o direito de propriedade são priorizados, ficando à margem estas questões do direito ambiental. Estes autores afirmaram que a criação da ReBio de Pinheiro Grosso não atende às diretrizes do SNUC.

A ocupação de áreas por órgãos privados dentro da unidade tem intensificado sua fragmentação, gerando degradações e prejuízos ao seu principal objetivo, a conservação da natureza local. No entanto, o fato de se tratar de atividade de utilidade pública, deve-se exigir ainda mais atenção dos gestores no que tange as formas de manejo adotadas, uma vez que isto pode servir de justificativa para a população local de se eximir das responsabilidades ambientais (CRUZ et al., 2013).

No que se refere à presença de famílias residentes, seja no entorno ou mesmo dentro da ReBio de Pinheiro Grosso, é importante destacar que muitas delas já residiam no local antes mesmo da criação da reserva. Porém, a irregularidade fundiária é uma realidade destas famílias ou daquelas que ocuparam novas áreas, mesmo até após a criação da ReBio. A realocação e a indenização para estas famílias são uma responsabilidade da Prefeitura. No entanto, diante das dificuldades enfrentadas pela gestão municipal, considerase pouco provável que tais medidas se tornem efetivas, embora sejam as medidas legais para tal situação (SILVA; SILVA, 2014). Neste contexto, é importante ressaltar que grande parte das UC brasileiras, especialmente os Parque Nacionais, as Estações Ecológicas e as Reservas Biológicas, enfrentam estes problemas fundiários desde a sua criação, um verdadeiro desafio que se acumula e se agrava com o passar dos anos (ROCHA et al., 2010).

Diante deste complexo cenário referente à presença de moradores, especialmente dentro dos limites de uma UC de Proteção Integral, Coelho e Rezende (2016) sugerem que a desapropriação de áreas deveria ser feita antes da criação da unidade, a partir de um planejamento, com o objetivo de evitar conflitos posteriores entre o poder público e particulares. De acordo com estes autores, o direito difuso ao meio ambiente ecologicamente equilibrado prevalece sobre a propriedade privada, ou seja, a desapropriação vem no sentido de resguardar garantias ambientais.

Neste contexto, embora Pivoto (2019) tenha analisado a situação fundiária do Parque Nacional da Serra do Cipó (MG) e destacado que, apesar criado em 1989, até hoje ainda existem conflitos territoriais entre o poder público e a população local. O autor ressalta o caso dos Parques Nacionais dos Lençois Maranhenses (MA) e das Montanhas de Tumucumaque (AP e PA) em que as populações tradicionais são colaboradoras para a proteção da biodiversidade e não um obstáculo à proteção do patrimônio natural do país. Neste sentido, Flores et al. (2009), apesar de considerarem delicada esta relação da comunidade local com as UC, destacaram a importância do envolvimento da população no processo de conservação assim como do trabalho constante de educação ambiental que 
deve ser realizado. Em ambas UC analisadas por estes autores, o Parque Tupancy e a Reserva da Lagoa do Peixe (RS), foram destacadas a importância da participação da comunidade local, seja na criação ou na conservação da natureza. Além disso, os autores também apontaram a necessidade de manutenção contínua das unidades, com monitoramento das áreas assim como o desenvolvimento de pesquisas científicas. Barros e Barbosa (2015) também destacaram a educação ambiental como relevante instrumento na conscientização da população diante da preservação dos recursos naturais.

No estudo realizado por Santiago et al. (2007) na ReBio Mata do Poço D’antas, Juiz de Fora (MG), foi levantada a possibilidade de recategorização da unidade para Parque Natural Municipal, devido a interferência antrópica na UC, como anteriormente comentado. Os autores ressaltaram que esta outra categoria ainda é um UC de Proteção Integral, com objetivo de preservação dos ecossistemas naturais, com permissão para uso no caso de pesquisas científicas, atividades de educação ambiental além da recreação em contato com a natureza e o turismo ecológico. Segundo os autores, os problemas da unidade em questão não se resolvem apenas por mudar a categoria da UC mas, com esta alteração inicial, o Plano de Manejo se torna mais flexível, permitindo a integração legal da comunidade. Da mesma forma, Silva e Silva (2014), para a ReBio de Pinheiro Grosso, destacaram, com base na análise em entrevistas realizadas, a necessidade de recategorização da unidade para que seja possível explorar os recursos naturais de maneira sustentável, conciliando o direito de propriedade das populações tradicionais com a proteção ambiental. Tal mudança torna-se oportuna tendo em vista o grau de interferência antrópica na unidade e a complexidade das questões fundiárias intrínsecas à ReBio em questão. Assim, diante da realidade apresentada da ReBio de Pinheiro Grosso, aponta-se como fundamental e primordial para a sua gestão, o trabalho de educação ambiental, especialmente a ser realizado com as comunidades vizinhas para que haja o início de um processo de conscientização sobre conservação da natureza da unidade.

Por meio da Análise Multicritério (AM), foram identificados 20,1 ha com Alto risco de pressão antrópica, o que representa 4,19\% da ReBio, enquanto que, 317,43 ha $(66,26 \%)$ com Baixo risco (Mapa 5). Ressalta-se que, nesta etapa da AM, a área antropizada, identificada pelo método da fotointerpretação, apresentou o valor de 141,56 ha $(29,55 \%)$. Observa-se que este valor foi diferente daquele encontrado pelo classificador (162 ha), isto porque o classificador identificou pixels com valor próximo ao da referida classe, onde possivelmente grande parte corresponde a clareiras no interior da mata (Mapa 2). Tal fato determina, inclusive, a robustez do método de classificação que foi capaz de identificar estas peculiaridades, não detectadas visualmente pelo método da fotointerpretação. Ao comparar o Mapa 2 com o Mapa 5, pode-se perceber que muitos destes pixels não considerados como área antropizada na fotointerpretação, foram classificados pela AM como Alto risco. A 
justificativa desta diferença se respalda também no uso de critérios para geração dos resultados, por parte da AM, que vai além apenas da resposta espectral do alvo, utilizada pelo classificador.

Embora a classe Alto risco de pressão antrópica tenha apresentado um valor aparentemente baixo (20,1 ha), deve-se lembrar que a UC em análise se trata de uma ReBio, do grupo de Proteção Integral.

Pina (2017) utilizou a AM na elaboração de mapas, a fim de indicar a necessidade de recuperação de áreas potenciais para a implantação de corredores ecológicos, demonstrando tal técnica eficaz para análises ambientais. Desta forma, o resultado obtido com a Análise Multicritério para a ReBio de Pinheiro Grosso auxiliou no conhecimento das áreas que estão com maior vulnerabilidade à pressão antrópica, sendo esta informação valiosa para ser utilizada em um zoneamento ambiental da unidade.

Mapa 5: Risco de Pressão Antrópica na Reserva Biológica de Pinheiro Grosso, Barbacena-MG.

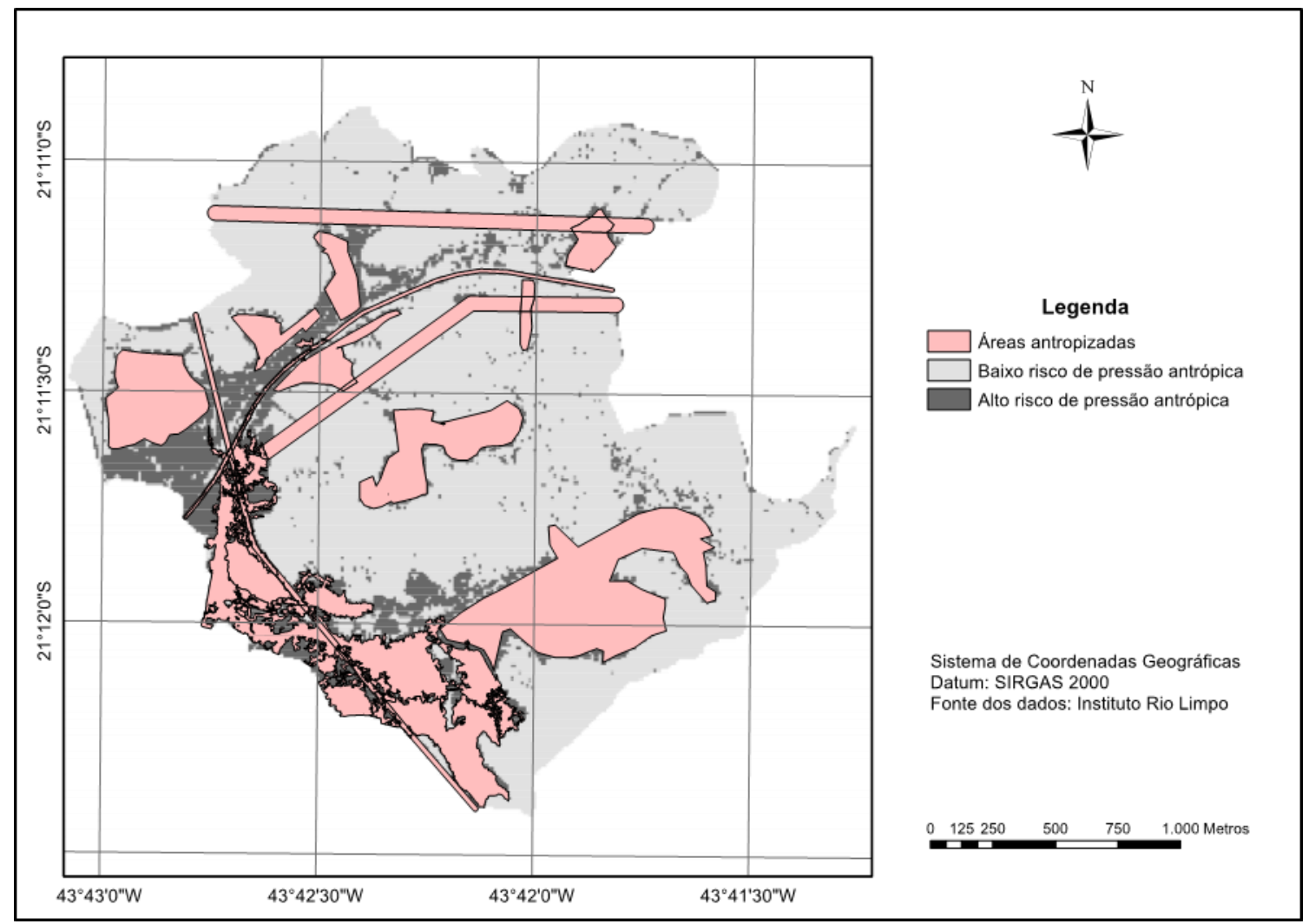

Org.: do Autor, 2019.

\section{CONSIDERAÇÕES FINAIS}

Embora mais de $66 \%$ da unidade (317 ha), tenham sido classificados como Vegetação, deve-se ressaltar que parte não corresponde à vegetação nativa, mas sim à floresta plantada de eucalipto. Ao que se refere aos outros $35 \%$ restantes da área da ReBio, aproximadamente 160 ha, os quais correspondem a áreas já antropizadas, deve-se considerar o fato de que 
uma comunidade rural se insere em seus limites e também na área limítrofe, o que tende a colocar a ReBio em questão em uma situação ainda mais vulnerável à alterações antrópicas. Assim, no que se refere ao uso e ocupação do solo, o cenário atual da ReBio Pinheiro Grosso é alarmante do ponto de vista de sua preservação enquanto UC pertencente ao grupo de Proteção Integral. Tal realidade dificulta o propósito da categoria de Reserva Biológica, sendo esta, a conservação da natureza.

Apesar de existir conflitos relacionados à propriedade privada nas proximidades da ReBio, áreas estas que correspondem à uma possível Zona de Amortecimento, sugere-se a delimitação oficial desta área para a unidade.

Sugere-se também a implementação de programas de educação ambiental, em caráter emergencial e contínuo, em todo o distrito cuja ReBio se insere. Desta forma, é possível transformar a população local que, desde a criação da ReBio tem impactado negativamente a unidade, em uma população ativa, participante e defensora dos recursos naturais desta UC.

A fiscalização e o monitoramento da ReBio de Pinheiro Grosso tornam-se fundamentais no sentido de ao menos evitar que novas ocupações da população ou de qualquer outra infraestrutura que exista próxima ou dentro dos limites desta UC venham a ocorrer e, assim, agravar a atual situação. Para tanto, o resultado da Análise Multicritério deste trabalho indicou as áreas de maior potencial de serem antropicamente alteradas, o que correspondeu a 20,1 ha $(4,19 \%)$ da ReBio.
Por fim, recomenda-se para a ReBio de Pinheiro Grosso a sua recategorização, transformando-a em uma unidade de Uso Sustentável, para que sejam cumpridos seus objetivos de gestão segundo a legislação brasileira.

\section{AGRADECIMENTOS}

Os autores agradecem ao Instituto Federal de Educação, Ciência e Tecnologia do Sudeste de Minas Gerais - Campus Barbacena pelo apoio financeiro na condução deste trabalho.

\section{REFERÊNCIAS}

ARAGÃO, J. G.; DUARTE, S. M. A. Uso das Geotecnologias para a Caracterização do Parque Estadual dois Irmãos, Recife-PE. Tecn-Lógica, Santa Cruz do Sul, v. 20, p. 26-32, $2016 . \quad$ https://doi.org/10. 17058/tecnolog.v20i1.6529

BALDWIN, B.; SCHERZINGER, R.; LIPSCOMB, D.; MOCKRIN, M.; STEIN, S. Planning for land use and conservation: Assessing GIS-based conservation software for land use planning. Research Note RMRS-RN-70, p. 1-33, 2014. https://doi.org/10.2737/RMRS-RN-70

BARBACENA. Lei Municipal no 2. 250, de 30 de novembro de 1987. $<$ https://leismunicipais.com.br/legislacaomunicipal/1535/leis-de-barbacena $>$ Acesso em: 20 de outubro de 2017.

BARROS, K. O. Anatomia de um crime ambiental. Tese (Doutorado em Ciência Florestal) - Universidade Federal de Viçosa - UFV. 2016.

BARROS, R. A.; BARBOSA, R. S. UNIDADES DE CONSERVACÃO: Um estudo sobre os impactos ambientais resultantes da extração de madeira na Reserva Biológica do GurupiMA. InterEspaço, v. 1, p. 270-292, 2015. https://doi.org/10.18766/24466549/interespa co.v1n2p270-292

BELLINASSI, S.; PAVÃO, A. C.; CARDOSO LEITE, E. Gestão e Uso Público de Unidades 
de Conservação: um olhar sobre os desafios e possibilidades. Rev. Brasileira de Ecoturismo, São Paulo, v. 4, p. 274-293, 2011.

https://doi.org/10.34024/rbecotur.2011.v4.59 18

BRASIL. Lei Federal no 4. 771, de 15 de setembro de 1965. Disponível em: $<$ https://www2.camara.leg.br/legin/fed/lei/1 960-1969/lei-4771-15-setembro-1965369026-publicacaooriginal-1-pl.html>. Acesso em: 08 out. 2017.

Lei $n^{\circ}$ 9. 985, de 18 de julho de 2000 .

Disponível em: <http://www.icmbio.gov. br/portal/images/stories/comunicacao/legisla caoambientalvolume1.pdf $>$. Acesso em: 12 de abril de 2019.

Lei no 11. 428, de 22 de dezembro de 2006. Disponível em: <https://www.camara. leg.br/proposicoesWeb/prop_mostrarintegra ?codteor $=645180>$. Acesso em: 17 de abril de 2019.

Lei $\mathrm{n}^{\circ}$ 12. 651, de 25 de maio de 2012.

Disponível em:

<http://www.botuvera.sc.gov.br/wpcontent/uploads/2014/09/lei-12651-2012codigo-florestal.pdf $>$. Acesso em: 08 de outubro 2017.

COELHO, H. A.; REZENDE, E. N. A efetiva implantação das unidades de conservação ambiental por meio da desapropriação. Rev. do Direito Público, v. 11, p. 165-195, 2016. https://doi.org/10.5433/1980-

511X.2016v11n2p165

CRUZ, J. S.; MELO, F. M; DIAS, N. O.; VALE, C. L. Avaliação da Efetividade da Implantação e Gestão da Reserva Biológica de Pinheiro Grosso- MG. In: VI SEMINÁRIO BRASILEIRO E I ENCONTRO LATINOAMERICANO SOBRE ÁREAS PROTEGIDAS E INCLUSÃO SOCIAL, Belo Horizonte. Anais... Belo Horizonte: p. 35-46. 2013.

DEBETIR, E. Gestão de unidades de conservação sob influência de áreas urbanas: diagnóstico e estratégias de gestão na Ilha de Santa Catarina Brasil. Tese (Doutorado em Engenharia Civil) - Universidade Federal de Santa Catarina - UFSC. 2006.

DOUROJEANNI, M. J.; PÁDUA, M. T. J. Biodiversidade: a hora decisiva. Curitiba: Ed. UFPR \& Ed. Fundação Boticário de Proteção da Natureza. 2001.

FARIA, H. H. Avaliação da efetividade de manejo de unidades de conservação: como proceder? In: CONGRESSO BRASILEIRO DE UNIDADES DE CONSERVAÇÃO, 1, 1997, Curitiba. Anais... IAP/UNILIVRE/Rede Nacional Pró-Unidade de Conservação. Belo Horizonte: p. 478-499. 1997.

FLORES, S. S. ; GRUBER, N. S.; MEDEIROS, R. M. V. Gestão e conflitos em Unidades de Conservação: gestão estratégica e operacional para preservação ambiental. Para onde!?, v. 5, p. 73-91, 2009. https://doi.org/10.22456/1982-0003. 22098

GOMES, D.; MARTINELLI, D. M. C. O código florestal e o uso da propriedade rural na perspectiva da (in)constitucionalidade da reserva legal. Cadernos de Direito, v. 12, p. 215-233, 2012. https://doi.org/10.15600/2238-1228/cd. v12n23p215-233

GONÇALVES, M. P.; BRANQUINHO, F T B; FELZENSZWALB, I. Uma Análise Contextual do Funcionamento Efetivo e Participação Popular em uma Unidade de Conservação: o caso da área de proteção ambiental de Petrópolis (Rio de Janeiro: Brasil). Soc. \& Nat., v. 23, p. 323-334, 2011. https://doi.org/10.1590/S198245132011000200014

IWAMA, A. Y.; LIMA, F. B.; PELLIN, A. Questão Fundiária em Áreas Protegidas: uma experiência no Parque Estadual da Pedra Branca (PEPB), Rio de Janeiro, Brasil. Soc. \& Nat., v. 26, p. 77-93, 2014. https://doi.org/10.1590/1982-451320140106

KHANDAY, M. Y.; JAVED, K. Prioritization of sub-watersheds for conservation measures in a semi arid watershed using remote sensing and GIS. Journal Geological Society of India, v. 88, p. 185-196, 2016. https://doi.org/10.1007/s12594-016-0477-7

MOURA, A. C. M. Reflexões metodológicas como subsídio para estudos ambientais baseados em Análise de Multicritérios. In: SIMPÓSIO BRASILEIRO DE SENSORIAMENTO REMOTO, Florianópolis. Anais... Florianópolis: INPE. 2007, p. 21-26. 2007.

PINA, G. F. Análise multicritério na identificação de áreas para a recuperação ecológica no plano de manejo ambiental municipal. (Dissertação em Agronomia) - Universidade Estadual Paulista - UNESP. 2017.

PIVOTO, A. S. "Aqueles que ainda resistem": 
um olhar sobre as disputas territoriais associadas ao processo de regularização fundiária do Parque Nacional da Serra do Cipó $\square$, MG, Brasil. Cad. de Geografia, v. 29, p. 420-440, 2019. https://doi.org/10. 5752/P.2318-2962.2019v29n57p420-440

REIS, T. E.; COSTA, V, C. Análise da vulnerabilidade na zona de amortecimento do Parque Estadual do Ibitipoca (MG), com o uso de SIG. Geosul, v. 32, p. 77-96, 2017. https://doi.org/10.5007/21775230.2017v32n63p77

RIBEIRO, M. F.; FREITAS, M. A. V.; COSTA, C. V. O desafio da gestão ambiental de zonas de amortecimento de unidades de conservação. In: SEMINÁRIO LATINOAMERICANO DE GEOGRAFIA FÍSICA, VI - SEMINÁRIO IBERO-AMERICANO DE GEOGRAFIA FÍSICA, 6, 2010, Coimbra. Anais... Coimbra: p. 1-11. 2010.

ROCHA, L. G.; DRUMMOND, J. A.; GANEM, R. S. Parques nacionais Brasileiros: problemas fundiários e alternativas para a sua resolução. Rev. Sociol. Polít., v. 18, p. 205-226, 2010 . https://doi.org/10.1590/S010444782010000200013

SANTIAGO, B. S.; REZENDE, R. F.; FERREIRA, C. C. M. Reserva Biológica Municipal de Poço D'Anta, Juiz de Fora/MG - aspectos da fragmentação de habitat e efeito de borda. Gaia Scientia, v. 1, p. 5366, 2007.

SANTOS, E. dos. O princípio da proibição do retrocesso socioambiental e o "novo" Código Florestal. Rev. Direito Eco. Socioambiental, v 3, p. 505-529, 2012. https://doi.org/10.7213/rev.dir.econ.socioam bienta.03.002.AO09

SILVA, C. F.; SILVA, H. A. DIREITO DE PROPRIEDADE E PROTEÇÃO AMBIENTAL: estudo de caso das unidades de conservação da natureza no município de Barbacena - MG. Vianna Sapiens, v. 5, p. 112-147, 2014.

SILVA, M. M.; MUCCI, J. L. N.; PELICIONI, M. C. F. A área de proteção ambiental 'Fazenda e Parque do Carmo': os problemas ambientais, as dificuldades de gestão e a influência na qualidade de vida da população. O Mundo da Saúde, v. 30, p. 544-550. 2006. https://doi.org/10.15343/01047809.200630.4. 3

SIMON, A. Aspectos socioambientais do Parque
Estadual da Serra da Tiririca. In: Plúrima Rev. da Faculdade de Direito da UFF, v. 24, p. 9-52, 2001.

TERRA, T. N.; ROZELY, F. S. Jureia: um bom (ou mau?) exemplo da influência de políticas sobre a conservação da natureza e a qualidade de vida. REU, v. 37, p. 37-49, 2011.

VENTICINQUE, E.; FORSBERG, B.; BARTHEM, R.; PETRY, P.; HESS, L.; MERCADO, A.; CAÑAS, C.; MONTOYA, M; DURIGAN, C; GOULDING, M. An explicit GIS-based river basin framework for aquatic ecosystem conservation in the Amazon. Earth Syst., v. 8, p. 651-661, 2016. https://doi.org/10.5194/essd-8-651-2016 